PAPER

\section{Carbon nanofibers obtained from electrospinning process}

To cite this article: Juliana Bovi de Oliveira et al 2018 Mater. Res. Express 5025602

View the article online for updates and enhancements.

\section{Related content}

Development of structurally stable
$\frac{\text { electrospun carbon nanofibers from }}{\text { polyvinyl alcohol }}$
Ashish Gupta and Sanjay R Dhakate
- Electrical property of macroscopic
$\frac{\text { graphene composite fibers prepared by }}{\text { chemical vapor deposition }}$
Haibin Sun, Can Fu, Yanli Gao et al.
Dielectric transition of polyacrylonitrile
derived carbon nanofibers
Jiangling Li, Shi Su, Lei Zhou et al.

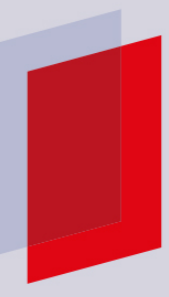

\section{IOP ebooks}

Bringing you innovative digital publishing with leading voices to create your essential collection of books in STEM research. Start exploring the collection - download the first chapter of every title for free. 


\section{Materials Research Express}

\section{PAPER}

\section{Carbon nanofibers obtained from electrospinning process}

RECEIVED

3 September 2017

REVISED

19 December 2017

ACCEPTED FOR PUBLICATION

29 December 2017

PUBLISHED

15 February 2018

\author{
Juliana Bovi de Oliveira ${ }^{1,4} \oplus$, Lília Müller Guerrini ${ }^{2}$, Silvia Sizuka Oishi ${ }^{3} \oplus$, Luis Rogerio de Oliveira Hein ${ }^{1}$, \\ Luíza dos Santos Conejo $^{1} \oplus$, Mirabel Cerqueira Rezende ${ }^{2}$ and Edson Cocchieri Botelho \\ 1 Universidade Estadual Paulista (UNESP), Faculty of Engineering, Materials and Technology Department, Guaratinguetá, Brazil \\ 2 Universidade Federal de São Paulo (UNIFESP), São José dos Campos, Brazil \\ 3 Instituto Nacional de Pesquisas Espaciais, São José dos Campos, Brazil \\ 4 Author to whom any correspondence should be addressed \\ E-mail: juliana_bovi@hotmail.com
}

Keywords: polyacrylonitrile, electrospinning, carbon nanofibers, carbonization

\begin{abstract}
In recent years, reinforcements consisting of carbon nanostructures, such as carbon nanotubes, fullerenes, graphenes, and carbon nanofibers have received significant attention due mainly to their chemical inertness and good mechanical, electrical and thermal properties. Since carbon nanofibers comprise a continuous reinforcing with high specific surface area, associated with the fact that they can be obtained at a low cost and in a large amount, they have shown to be advantageous compared to traditional carbon nanotubes. The main objective of this work is the processing of carbon nanofibers, using polyacrylonitrile (PAN) as a precursor, obtained by the electrospinning process via polymer solution, with subsequent use for airspace applications as reinforcement in polymer composites. In this work, firstly PAN nanofibers were produced by electrospinning with diameters in the range of $(375 \pm 85) \mathrm{nm}$, using a dimethylformamide solution. Using a furnace, the PAN nanofiber was converted into carbon nanofiber. Morphologies and structures of PAN and carbon nanofibers were investigated by scanning electron microscopy, Raman Spectroscopy, thermogravimetric analyses and differential scanning calorimeter. The resulting residual weight after carbonization was approximately $38 \%$ in weight, with a diameters reduction of $50 \%$, and the same showed a carbon yield of $25 \%$. From the analysis of the crystalline structure of the carbonized material, it was found that the material presented a disordered structure.
\end{abstract}

\section{Introduction}

Carbon materials present scientific and technological interests, due to their wide applicability in different areas of knowledge. These materials are mostly applied in airspace, automotive, marine, medical and electrochemical fields as well as in the nuclear industry [1,2].

Carbon materials present advantageous properties, such as, chemical inertia, resistance to the most of common corrosive reagents and stability in a broad range temperatures under inert atmosphere (sublimating at $3900 \mathrm{~K}$ under atmospheric conditions and melting temperature at $4800 \mathrm{~K}$ ). Furthermore, the carbon has a low density in comparison with metals and alloys, making it appropriate for compact and lightweight applications. Thus, among the carbon materials nowadays available can be cited carbon foam, carbon nanofibers, carbon nanotubes and carbon matrix composites [3-5].

As result of their excellent multifunctional properties and various technological applications, especially in airspace and biomedical fields, the processing of polymeric materials on micrometric and nanometric dimensions come lately, attracting more attention to specific purposes. Examples in this area are the carbon micro and nanofibers, which have been widely studied, because they present excellent thermal, electrical and mechanical properties. These fibers have good mechanical strength, good electrical and thermal conductivities, high temperature resistance, great chemical stability and wide surface area, and yet can be manufactured easily and in large quantities. The carbon micro and nanofibers also have the advantage of having low cost compared 
with carbon nanotubes. Thus, these materials may be applied in several areas, including reinforcing materials, catalyst supports, high temperature filter, in orthopedic implants and others [6-9].

Still in the field of nanotechnology, which has shown an accelerated development in experimental area, we highlight contributions involving nanocomposites, cosmetics, flame resistant materials, materials with electrooptical and antibacterial properties, among others. Basically, the nanoscale is a transition zone between the macro and molecular levels. Nanocomposite materials appear as suitable alternatives to overcome the limitations of microcomposites. It is found that the interactions at the interfaces of composites are improved when there is the use of nanomaterials in the matrix of composites, with the consequent improving of their properties [10-13].

Inside in this context, the electrospinning via polymer solution has been considered an effective alternative to produce uniform and continuous micrometric and nanometric fibers. This technique highlights due to its easily of using and experimental condition control. In this process the polymer solution is in a capillary tube which is connected to an electrode and the same is coupled to a source of high voltage that can be positive or negative. At first, the solution displays a format of a drop at the end of the capillary. Then, the drop surface extends to produce a cone (called Taylor cone) as result of the increased voltage. Subsequently, a jet of solution is ejected. In this step, the solvent evaporates and the polymer solidifies, producing a fiber mat that is deposited on a metallic collector under grounding. During this process, some factors may influence the morphology and structure of micro and nanofibers produced. Among these the main processing parameter are: the applied voltage, the solution flow in the capillary, the concentration of polymer solution, and the working distance. The working distance is defined as the distance between the exit of solution and the collector [14-17].

Among the polymeric precursors used to manufacture carbon nanofibers through the electrospinning process may be considered the polyacrylonitrile (PAN), because it present a high carbon yield in the carbonization heat treatment and simple preparation process [6, 18].

This work has as objective the production of carbon nanofibers based on carbonization of PAN mat precursor, obtained by electrospinning process of polymer solution. In order to obtain the PAN nanofiber mat, a study concerning the main variables related to the electrospinning process to obtain micrometers and nanometers with homogeneous distribution and free of defects was done. The characterization of PAN mats considered the thermal behavior (by thermogravimetric and differential scanning calorimetry (DSC) analyses), morphological aspects (by scanning electron microscopy, SEM) and crystalline structure (by Raman spectroscopy).

\section{Materials and methods}

\subsection{Materials}

The PAN used in this work was supplied by Radici company in powder form. The dimethylformamide solvent (DMF), with concentration $\geqslant 99 \%$, was supplied by Mallinckrodt Chemicals company.

\subsection{The solution preparation}

A solution containing 4\%, 5\% and 6\% (wt/wt) of PAN in DMF was prepared. The homogenization of this solution was guaranteed by constant agitation for $3 \mathrm{~h}$, at room temperature.

\subsection{Electrospinning}

The electrospinning system used in this work (figure 1$)$ consists of a high voltage source $(0-30 \mathrm{kV})$ the Faísca brand, a cylinder underground (collector) that is rotated by a gear motor the Tekno brand, MRT910 model (0-300 rpm) and a Tekno brand CVET2002 model controller, a glass syringe with $20 \mathrm{ml}$ that has a stainless steel fitting and a stainless needle Hamilton type. To control the humidity during this process was used a dehumidifier Thermomatic brand, Desidrat Plus model and thermohygrometer watch Minipa brand MT-241 model. To quantify the cylinder speed was used a tachometer Minipa brand and MDT2238A model.

The parameters used in the processing of PAN blankets by electrospinning were: a stainless steel needle of $10 \mathrm{~mm}^{-1}$ long and $1.5 \mathrm{~mm}$ diameter, a cylinder rotation around $24 \mathrm{rpm}$, applied voltage range of $18.8-27.1 \mathrm{kV}$, working distance of $10 \mathrm{~cm}$, humidity range of $35 \%-48 \%$, room temperature range of $29.4-37.5^{\circ} \mathrm{C}$ and collection time of 1,2, 6 and $12 \mathrm{~h}$. These parameters were stablished in a previous work of the research group [19]. The equipment used in the treatment of the mats does not have a control of solution flow. The exit of the solution of the needle tip is controlled by gravity $\left(9.8 \mathrm{~m} \mathrm{~s}^{-2}\right)$. 


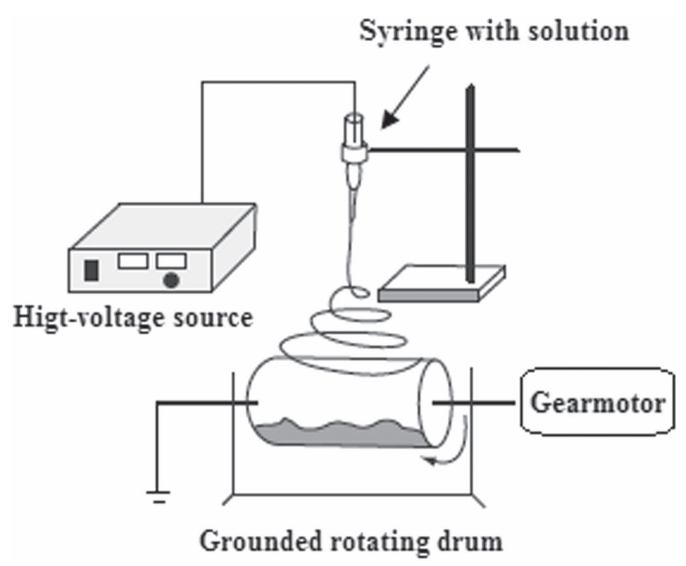

Figure 1. Schematic diagram of the electrospinning system used.

\subsubsection{PAN characterization}

The thermogravimetric analyses (TGA) were conducted in a SEIKO SII Nanotechnology equipment, EXSTAR 6000 (TG/DTG6200) model, using about $8 \mathrm{mg}$ of PAN mat in a platinum pan, at a heating rate of $15^{\circ} \mathrm{C} \mathrm{min}^{-1}$, under a nitrogen flow of $100 \mathrm{ml} \mathrm{min}^{-1}$, in the temperature range of $30-1000{ }^{\circ} \mathrm{C}$.

The DSC analyses were performed in a TA Instruments equipment, Q20 series, with controlled nitrogen flow of $40 \mathrm{ml} \mathrm{min}^{-1}$, using approximately $5.7 \mathrm{mg}$ of PAN mat, and the heating rate of $10^{\circ} \mathrm{C} \mathrm{min}^{-1}$, in the temperature range of $25-400{ }^{\circ} \mathrm{C}$.

The morphological analyses of nanofibers were performed in a scanning electron microscope of ZEISS, EVO $\mid$ LS15 model, equipped with OXFORD link for microanalysis and tungsten filament. The analysis conditions were electron beam with a resolution of $20 \mu \mathrm{m}, 10 \mathrm{kV}$ and vacuum of $10^{-3} \mathrm{~Pa}$. The mats were cut, pasted into a double-sided tape of carbon and metallized with gold. The Image J program was used for the image analyses.

\subsection{Carbonization and characterization of carbon fibers}

The PAN fibers obtained from the electrospinning process were carbonized in an electric furnace with cylindrical chamber of quartz, under constant flow of nitrogen. During this step, it was used the heating rate of

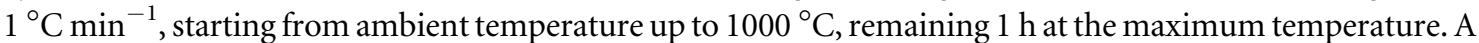
stainless steel screen 304 of 100 mesh, diameter of wire of 0.10 and $0.154 \mathrm{~mm}$ opening was used to wrap and protect the nanofibers to avoid that they do not flew during the carbonization process.

\subsubsection{Characterization method of the carbonized material}

Morphological analyses of carbon nanofibers was held in a scanning electron microscope of ZEISS, model EVO| LS15 with tungsten filament. Just the same was used in the PAN mats characterization. The carbon mats were glued on a double-sided tape of carbon and metallized with gold. The image analyses were also performed using the Image J program.

In this research work, analyses of the carbon mats by Raman spectroscopy was also performed on an optical microscope Renishaw 2000, with laser at $514.5 \mathrm{~nm}$. Calibration was previously performed with diamond.

\section{Results and discussion}

\subsection{PAN nanofibers produced by eletrospinning}

In this work 3 processing parameters of the electrospinning process were evaluated for production of the nanofibers: solution concentration, voltage and processing time.

\subsubsection{Solution concentration}

The solution concentration used to produce nanofibers were $4 \%, 5 \%$ and $6 \%$ (wt/wt). Figure 2 shows the mats based on PAN fibers produced by electrospinning process, using PAN concentrations of $4 \%, 5 \%$ and $6 \%$ (wt/ wt), processed under the conditions described in item 2.3.

Concerning about the use of $4 \% \mathrm{wt} / \mathrm{wt}$ PAN/DMF contents was necessary to raise the solution voltage to $27.1 \mathrm{kV}$ for the production of PAN fiber jet in the needle. This problem occurs due to the low concentration of polymer in solution and consequently its low viscosity. 


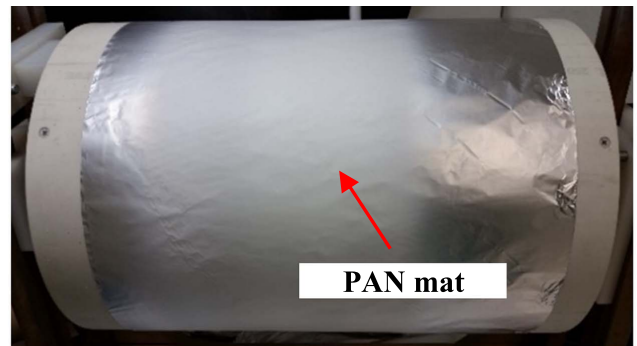

(a)

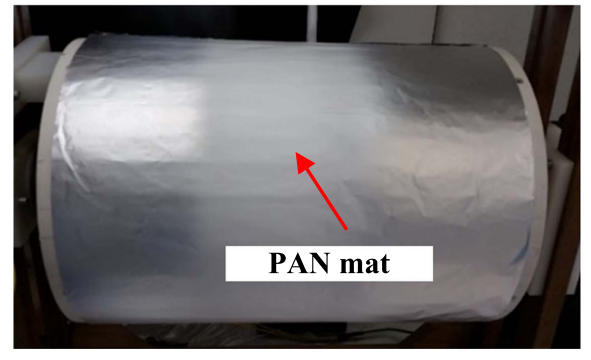

(b)

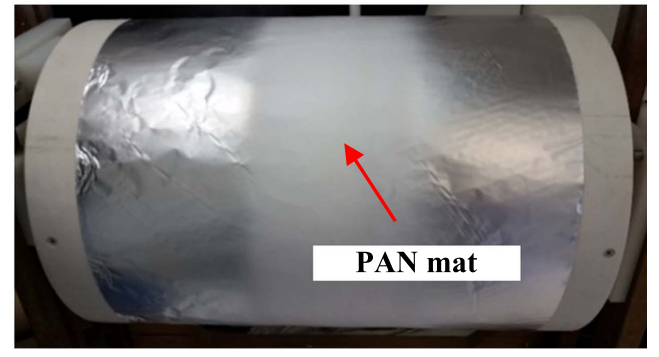

(c)

Figure 2. PAN mats obtained with PAN/DMF solutions of: (a) 4\%, (b) $5 \%$ and (c) $6 \%$ (wt/wt).

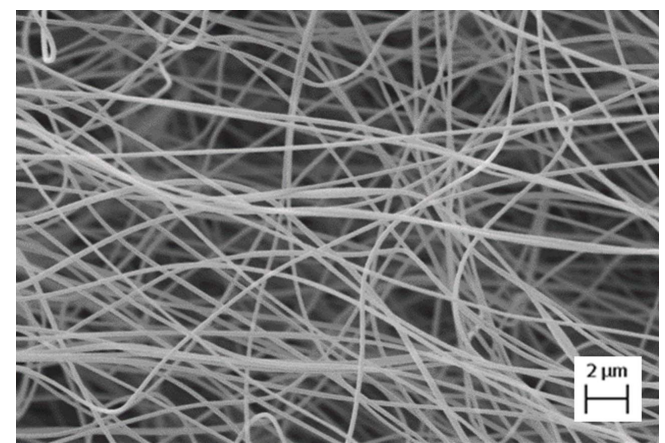

(a)

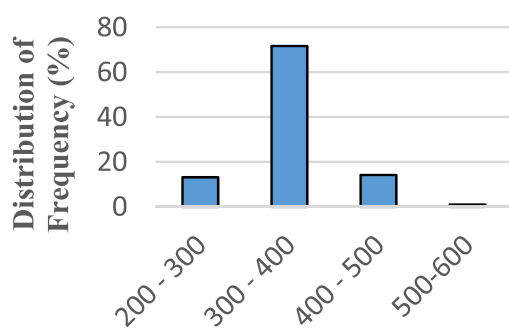

Fibers Diameter (nm)

(b)

Figure 3. (a) SEM of PAN nanofibers obtained from electrospinning with voltage of $18.8 \mathrm{kV}$ and (b) frequency distribution of the fibers.

After performing the electrospinning process, it was measured the thickness of mats, using a micrometer device. The mats based on $4 \%, 5 \%$ and $6 \%(\mathrm{wt} / \mathrm{wt})$ solutions presented, respectively, the following average thickness values: $(0.069 \pm 0.004) \mathrm{mm} ;(0.050 \pm 0.002) \mathrm{mm}$ and $(0.066 \pm 0.004) \mathrm{mm}$. It was observed that the thickness of mats produced with the $5 \%$ (wt/wt) PAN/DMF solution presented lower values when compared with the others, but all values are similar. However, it was verified that the process that used $4 \%$ (wt/wt) solution consumed twice more than the mat obtained from electrospinning process using $6 \%$ (wt/wt) PAN solution, keeping the same final thickness. Thus, in order to promote the PAN mat production with the solution containing $4 \%$ (wt/wt) of PAN, high voltages and more solution were required, being a disadvantage. Considering these arguments, in this work the mats based on PAN fibers were produced with $6 \%$ (wt/wt) PAN/ DMF solution.

\subsubsection{Voltage variation in the electrospinning process}

In order to produce PAN fibers with smaller diameters, in the electrospinning process were tested the voltages of $18.8,20.4$ and $21.8 \mathrm{kV}$. Applying the voltages previously cited and keeping constant the other parameters (concentration of solution in $6 \%(\mathrm{wt} / \mathrm{wt}$ ); drum rotation of $24 \mathrm{rpm}$, work distance of $10 \mathrm{~cm}$ and time collection in $2 \mathrm{~h}$, humidity of $35 \%$; and temperature of $37.5^{\circ} \mathrm{C}$ it was possible to obtain PAN nanofibers as depicted in figures 3-5. These figures show the morphologies of fibers and histograms of distribution of frequency as a function of fiber diameter. 


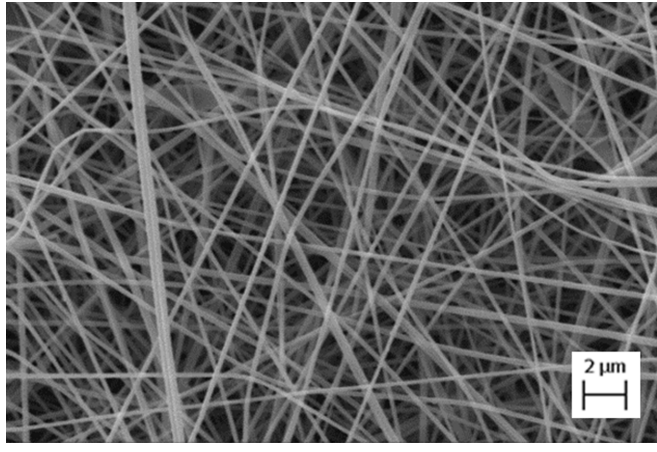

(a)

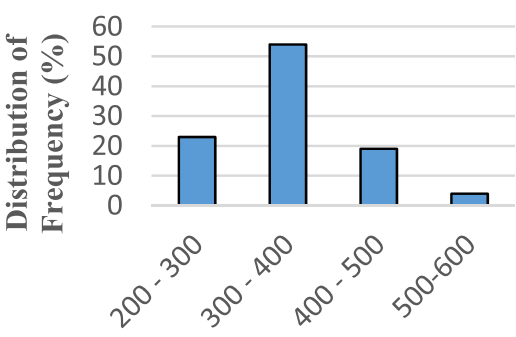

Fibers Diameter (nm)

\section{(b)}

Figure 4. (a) SEM of PAN nanofibers obtained from electrospinning with voltage of $20.4 \mathrm{kV}$ and (b) frequency distribution of the fibers.

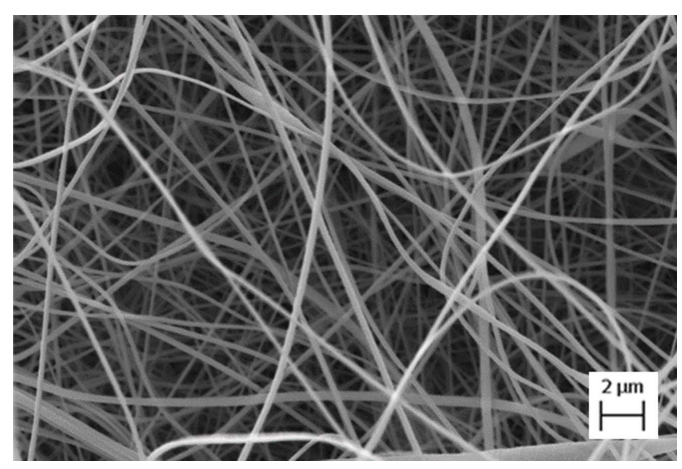

(a)

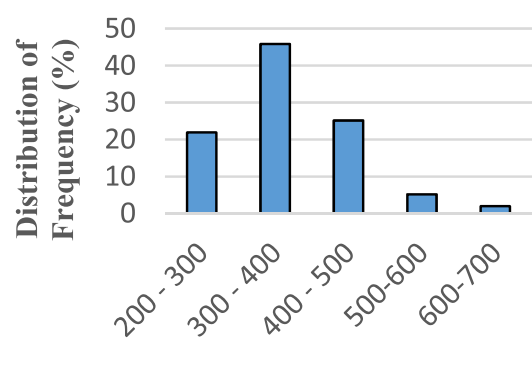

Fibers Diameter (nm)

(b)

Figure 5. (a) SEM of PAN nanofibers obtained from electrospinning with voltage of $21.8 \mathrm{kV}$ (b) and histogram of frequency distribution.

Figures 3(b), 4(b) and 5(b) show the highest frequency of diameters in the range of 300-400 nm for the three different voltages used. According to figures 3(a), 4(a) and 5(a), the morphologies of the fibers are similar, without defects. The average diameters measured were $(359 \pm 49) \mathrm{nm},(359 \pm 73) \mathrm{nm}$ and $(373 \pm 82) \mathrm{nm}$ for fibers obtained at $18.8 \mathrm{kV}, 20.4 \mathrm{kV}$ and $21.8 \mathrm{kV}$, respectively. Comparing the diameters of the fibers obtained with different voltages no significant variation is observed. Since the voltage of $21.8 \mathrm{kV}$ remained more stable for a longer period of processing time, this value was used in this work.

\subsubsection{Processing time}

The variation of processing time is extremely important because this parameter determines the amount of fibers obtained for the subsequent carbonization heat treatment. Thus, with this purpose in this work was first used PAN/DMF solution with concentration of $(6 \% \mathrm{wt} / \mathrm{wt})$ for $1 \mathrm{~h}$, and the parameters used in the electrospinning process were: stainless steel needle of $10 \mathrm{~mm}$ length and $1.5 \mathrm{~mm}$ diameter; drum rotation of $24.1 \mathrm{rpm}$; applied voltage of $21.8 \mathrm{kV}$ and the working distance of $10 \mathrm{~cm}$; humidity $32 \%$ and temperature $33.5^{\circ} \mathrm{C}$. However, when the PAN mat with thickness of $(0.041 \pm 0.002) \mathrm{mm}$ was carbonized it was verified no carbon yield in the end of the heat treatment. The same behavior happened with the mat electrospinned for $2 \mathrm{~h}$, using the same processing parameters cited. Despite greater thickness $((0.066 \pm 0.004) \mathrm{mm})$ when compared to the mat electrospinned for $1 \mathrm{~h}$, this thicker sample was not proper for the carbonization yet due probably to the insufficient mass of PAN mat exposed to the heat treatment.

Due to this difficulty, it was carried out the electrospinning of PAN/DMF solution of $6 \%$ (wt/wt) for $6 \mathrm{~h}$. In this case the thickness reached the value of $(0.082 \pm 0.003) \mathrm{mm}$, using the following parameters: applied voltage of $22.2 \mathrm{kV}$, humidity of $48 \%$ and temperature of $31.6^{\circ} \mathrm{C}$.

The PAN nanofiber mat obtained in 6 h of electrospinning, after carbonization, presented a good carbon yield. In order to increase the PAN mat production it was used $12 \mathrm{~h}$ of electrospinning. In this case, using the applied voltage of $21.8 \mathrm{kV}$; humidity of $43 \%$ and $29.4{ }^{\circ} \mathrm{C}$. In this condition, the thickness of the mat produced increased for $(0.103 \pm 0.003) \mathrm{mm}$. The increased time of electrospinning process also resulted in an increase in 


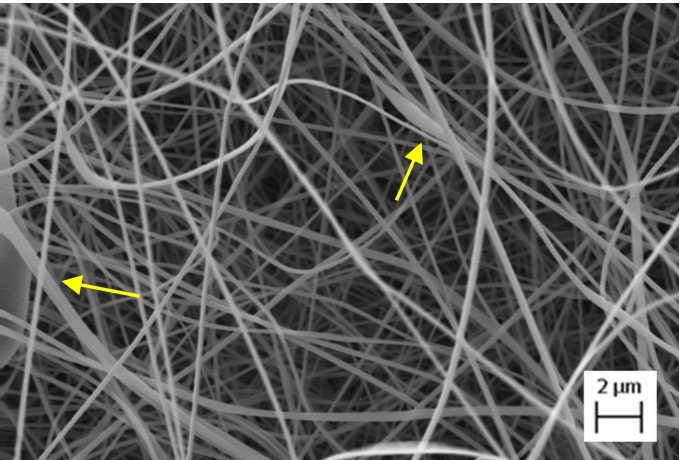

(a)

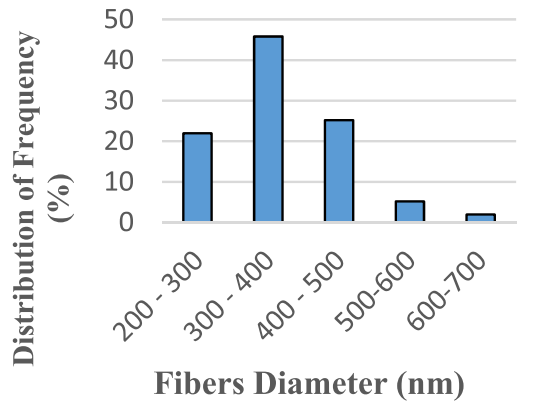

(b)

Figure 6. (a) SEM of PAN nanofibers obtained after $12 \mathrm{~h}$ in electrospinning process and (b) histogram of diameter distribution.

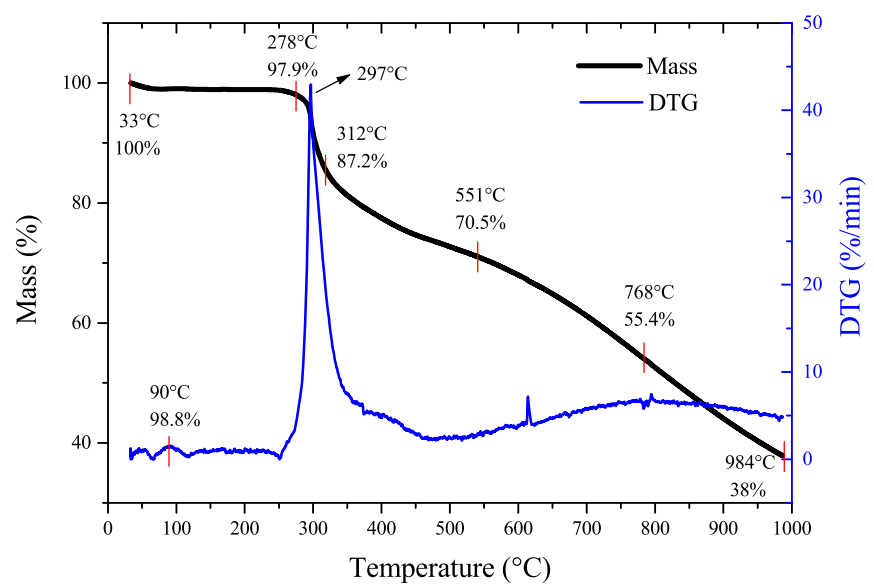

Figure 7. TGA/DTG of PAN fiber.

the scattering of PAN nanofibers on the aluminum foil, used as a collector, hindering a significant increase in the final material thickness. Nevertheless, the fibers produced by this process, after carbonization, resulted in carbon mats.

Figure 6 depict, respectively, the morphologies obtained by SEM and the histograms of the distribution frequency of the fibers obtained in the electrospinning of $12 \mathrm{~h}$. As can be observed in figure 6(a), the fiber structure presents few defects such as junctions (indicated by arrows). These defects may occur when the nanofibers are deposited on the collector, and these one get in contact with each other under the influence of solvent still present, join or coalesce each other. However, it was verified that this fiber generates mats almost no defects like drops.

According to the results observed in figure 6(b), it is seen that the highest frequency of diameters is in the range of 300-400 $\mathrm{nm}$ (with average diameters equal to $(375 \pm 85) \mathrm{nm}$ ). According to the literature [20, 21], the distribution of diameters of PAN nanofibers, produced by electrospinning, is in the range of 0-2000 nm, with an average diameter between 100 and $280 \mathrm{~nm}$.

\subsubsection{Thermal behavior of PAN blankets produced by electrospinning process}

Figure 7 presents the thermal decomposition obtained by TGA for PAN fibers processed from the temperature range of $30-1000{ }^{\circ} \mathrm{C}$, at a heating rate of $15^{\circ} \mathrm{C} \mathrm{min}{ }^{-1}$, under a nitrogen flow of $100 \mathrm{ml} \mathrm{min}{ }^{-1}$.

According to the TGA, the thermal degradation of PAN fiber occurs in at least 4 different stages: 1st stagepresence of moisture; 2nd stage — presence of solvent; 3rd stage_-degradation of the PAN fiber and 4th stagegases that are volatilized, as identified in accordance with the DTG results. Initially, there is a weight loss of $1.2 \%$ in the TGA curve, as shown in the derivative curve. This variation occurs at $90^{\circ} \mathrm{C}$, possibly, due to the presence of moisture or low molecular weight fractions in the mat. Then, it is observed a second weight loss of around $0.9 \%$, that occurs between the temperatures of 150 and $230{ }^{\circ} \mathrm{C}$, which may be related to the presence of DMF (solvent used in the electrospinning process). According to the literature, the boiling temperature of DMF is 


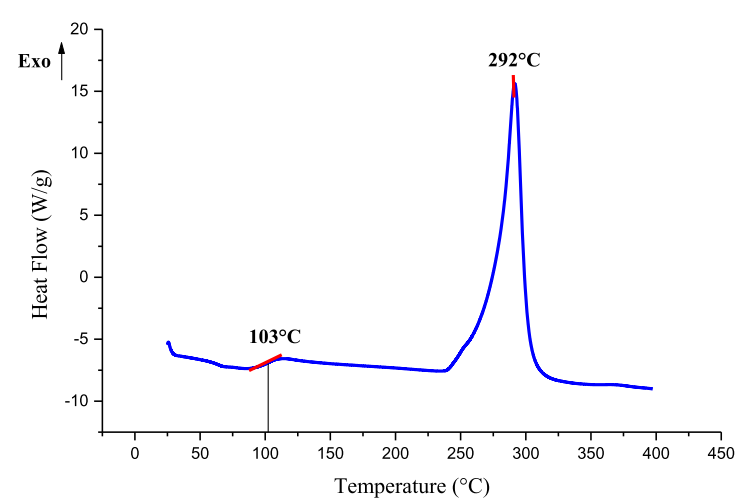

(a)

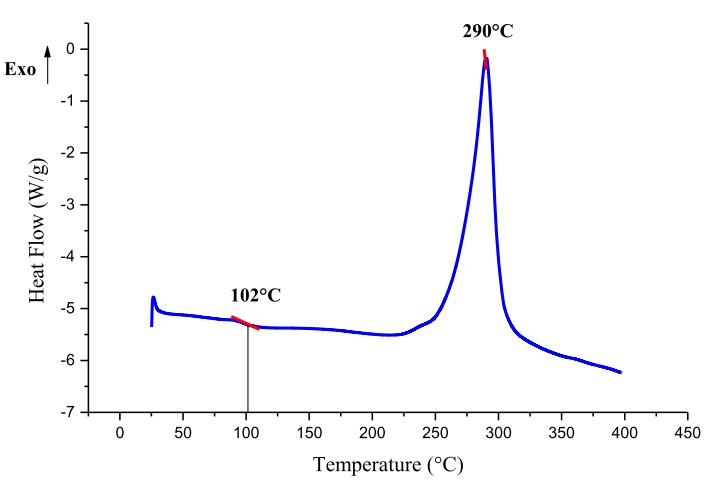

(b)

Figure 8. DSC curve for PAN fiber obtained after electrospinning for: (a) $6 \mathrm{~h}$ and (b) $12 \mathrm{~h}$.

equal to $153{ }^{\circ} \mathrm{C}$ [22]. In the temperature of $278^{\circ} \mathrm{C}$, begins the degradation of PAN fibers; the DTG curve shows that this step finalizes at $312{ }^{\circ} \mathrm{C}$. The weight loss of PAN starts at $278{ }^{\circ} \mathrm{C}$, and goes until about $1000{ }^{\circ} \mathrm{C}$, where is consumed $59.9 \%$ of the PAN weight. These losses are attributed to different gases that are volatilized during the decomposition of PAN, such as $\mathrm{H}_{2} \mathrm{O}, \mathrm{CO}_{2}, \mathrm{CO}, \mathrm{CH}_{4}, \mathrm{NH}_{3}$ and $\mathrm{HCN}$ [23, 24]. According to Xue et al [25], the formation of $\mathrm{NH}_{3}$ and $\mathrm{HCN}$ is originated from the terminal amino groups of the cyclized structure of the PAN copolymer. In accordance with the literature, the onset of PAN degradation occurs around $160{ }^{\circ} \mathrm{C}$ [26]. Other authors, such as Brito Jr et al [27], reported that was not observed by TGA technique a significant weight loss below $280^{\circ} \mathrm{C}$.

The DSC curves of PAN fibers produced by electrospinning are presented in figure 8 . Figure 8 (a) shows the thermal behavior of PAN fiber obtained from solution of $6 \%$ (wt/wt) processed for $6 \mathrm{~h}$. Figure 8(b) presents the results of PAN fiber with concentration of $6 \%$ (wt/wt) electrospinned for $12 \mathrm{~h}$. According to these curves, the PAN presents a glass transition temperature value (Tg) well defined. The Tg of PAN fiber, obtained from electrospinning process of $6 \mathrm{~h}$, is $103^{\circ} \mathrm{C}$. This value is very close to the Tg value obtained for the PAN fibers from electrospinning process of $12 \mathrm{~h}$, which is $102^{\circ} \mathrm{C}$. This Tg values are found slightly lower than that presented in the literature, i.e., around $125^{\circ} \mathrm{C}[28]$.

Both curves observed (figure 8) present a peak of degradation (exotherm) with a maximum temperature of $292^{\circ} \mathrm{C}$ (starting in $238^{\circ} \mathrm{C}$ and ending in $329^{\circ} \mathrm{C}$ ) to the mat after electrospinning for $6 \mathrm{~h}$ and a peak with a maximum temperature of $290^{\circ} \mathrm{C}$ (with onset in $222^{\circ} \mathrm{C}$ and endset in $323^{\circ} \mathrm{C}$ ) for the mat after electrospinning for $12 \mathrm{~h}$. The degradation values presented in both graphs are close. These values are in accordance with the literature for PAN [29], which reports value of $293^{\circ} \mathrm{C}$ and also the value of PAN degradation temperature found in figure 7, which is $297^{\circ} \mathrm{C}$. The enthalpy of degradation reaction for PAN obtained from the area contained under the exothermic peak is $827.4 \mathrm{~J} \mathrm{~g}^{-1}$ (figures 8(a)), and $629.1 \mathrm{~J} \mathrm{~g}^{-1}$ (figure 8(b)), considering PAN fibers obtained after $6 \mathrm{~h}$ and $12 \mathrm{~h}$, respectively, being found in the work of Santos [29] a value lower but closed than verified in this study, equal to $515 \mathrm{~J} \mathrm{~g}^{-1}$.

Based on figure 8 it was not possible to detect a peak related to the melting of PAN, only the peaks relating to degradation. This is possibly as a consequence of the final degradation reaction occurs at temperatures near to the melting temperature $\left(320-326^{\circ} \mathrm{C}\right)$, as mentioned in the literature [30].

\subsection{Carbon nanofiber}

The PAN mats produced by electrospinning for 6 and $12 \mathrm{~h}$ were carbonized in an electric furnace. After carbonization process, these blankets exhibit black color, and fragile behavior (brittle) and weight loss of approximately $75 \%$. The high weight loss exhibited by carbon nanofiber blanket is justified probably by the nonexecution of the thermal stabilization step of PAN. Thermal stabilization typically occurs between the temperature range of $200-300^{\circ} \mathrm{C}$, with the main purpose to make the PAN precursor fibers stable for the subsequent heat treatment process, preventing the melting of PAN during the carbonization process, as reported in the literature [31].

Figure 9(a) shows the morphology of PAN fiber after electrospinning for $12 \mathrm{~h}$ and figure 9(b) presents the same mat after carbonization process originating carbon nanofibers, both assessed by SEM. As can be seen from figure 9(a), PAN mat has a constitution of well defined and spaced fibers, overlapped in a random arrangement, forming different planes. However, figure 9(b) depicts a more homogeneous structure generated after the carbonization of the PAN fibers into carbon fibers. In other words, in his case it is observed a more compact 


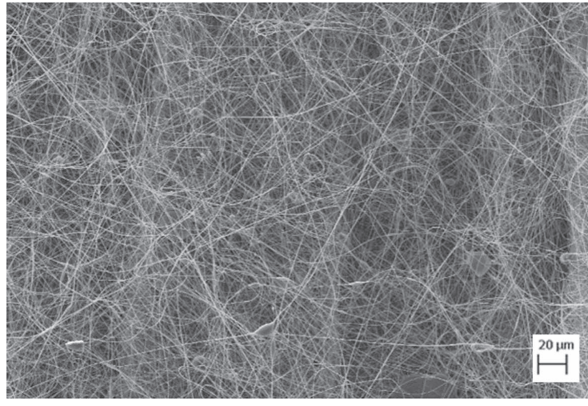

(a)

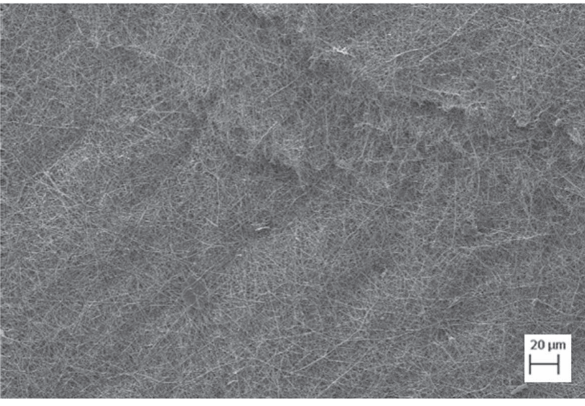

(b)

Figure 9. SEM of (a) PAN fibers obtained after electrospinning; (b) PAN fibers after carbonization (carbon nanofibers).

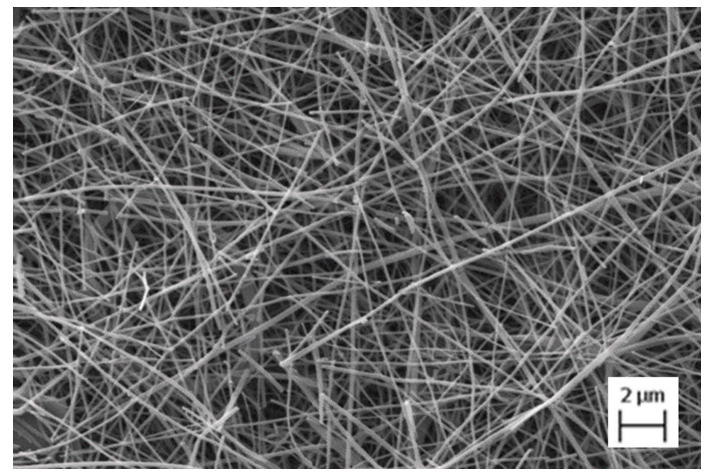

(a)

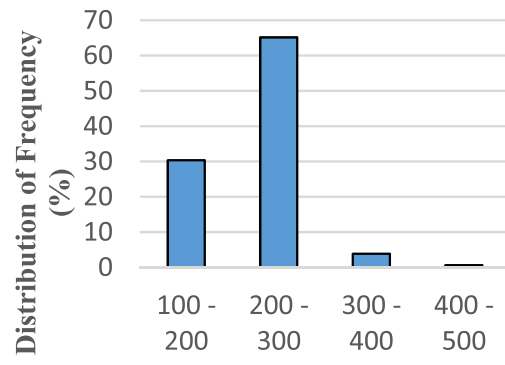

Fibers Diameter (nm)

(b)

Figure 10. (a) SEM of carbon nanofibers and histogram of diameter distribution of carbon nanofibers.

material, not being possible to distinguish one fiber from the other. Figure 10(a) presents the same carbon nanofiber, analyzed in higher magnification. This figure shows the presence of fibers separated and well defined, superposed in several planes. It may also be seen that occurred the breakage of some fibers after carbonization and that they presented, visibly, a reduction in their diameters. This break probably happened due to the release of volatile materials of low molar mass. This reduction in diameter is expected due to volumetric shrinkage that the polymeric materials may suffer when they are converted in carbonaceous materials, often this shrinkage is of approximately $30 \%$ by volume [32]. This change can also be observed in the histogram of diameter distribution of the fibers, according to figure 10 (b).

According to figure 10(b), it was observed that the carbon nanofibers obtained from PAN fibers exhibit more homogeneous dimensions, with $65 \%$ of the fibers presenting diameters values in the range of $200-300 \mathrm{~nm}$. The average diameter of these fibers is equal to $(186 \pm 45) \mathrm{nm}$. This figure shows also that the carbonized fibers present a decrease of approximately $50 \%$ in their diameters. According to the literature this reduction may be attributed to the heat treatment which provides the weight loss with the release of volatiles such as ammonia, hydrocyanic acid and water, reducing, thus, the diameter of fibers [21]. According to Adabi [21], it is possible to use nanofibers that were processed by electrospinning and subsequently carbonized, such as nanoelectrodes, but to function as a nanoelectrode, the fiber diameters have to be between 75 and $80 \mathrm{~nm}$, because below or above these values there is a decrease in the conductivity of the carbon fiber, not serving the function in question. thas been the application for composite reinforcement area requires that the blanket has made a suitable size so it can be, for example, used in a press with a composite. The carbonized blankets had small dimensions, since the tubular furnace used for the procedure had a diameter of approximately $60 \mathrm{~mm}$.

\subsubsection{Raman spectroscopy analysis of carbon nanofiber}

The carbon element can present different crystalline and morphological structures with different characteristics and Raman spectroscopy is usually used for qualitative evaluation of the crystallographic ordering concerning about carbonaceous materials or to evaluate the effect of heat treatment on cokes or organic precursors. The D band at $\sim 1360 \mathrm{~cm}^{-1}$ is related to defects such as edge effects, impurities and finite size, corresponding to disordered structure of carbon and reflecting the $\mathrm{sp}^{2}$ vibration of the ring. The $\mathrm{G}$ band at $\sim 1590 \mathrm{~cm}^{-1}$, reflects 


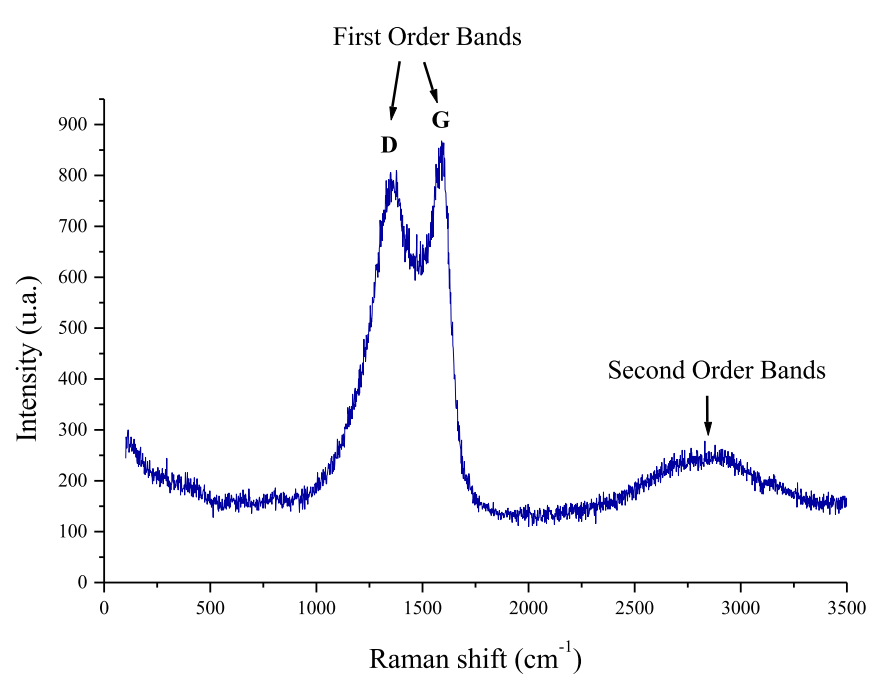

Figure 11. First and second order Raman spectrum of carbonized material.

Table 1. D and $\mathrm{G}$ bands positions and $I_{\mathrm{D}} / I_{\mathrm{G}}$ intensity ratio of the carbonized nanofiber (measured in three different places).

\begin{tabular}{lccc}
\hline Measure & D band $\left(\mathrm{cm}^{-1}\right)$ & $\mathrm{Gband}\left(\mathrm{cm}^{-1}\right)$ & $I_{\mathrm{D}} / I_{\mathrm{G}}$ \\
\hline 1 & 1361.1 & 1587.2 & 0.918 \\
2 & 1359.5 & 1590.3 & 0.930 \\
3 & 1358.1 & 1590.3 & 0.914 \\
Average & $1359.6 \pm 1.5$ & $1589.3 \pm 1.8$ & $0.921 \pm 0.009$ \\
\hline
\end{tabular}

the degree of graphitization of the studied material (crystalline and atomic arrangements) [33-35]. The most important parameter calculated with this technique is the $I_{\mathrm{D}} / I_{\mathrm{G}}$ intensity ratio which is useful to estimate the degree of ordering in carbonaceous material [36]. The second order Raman is related to the stacking disorder along the crystallographic $c$-axis [37].

Figure 11 shows the first and second order Raman spectrum of the carbonized material which displays two broad $\mathrm{D}$ and $\mathrm{G}$ bands characteristic of disordered carbon. In addition, the second order region does not show any band development which indicates the heat treatment temperature used $\left(100{ }^{\circ} \mathrm{C}\right)$ is not enough to improve crystallographic ordering of carbon nanofiber.

Table 1 contains the positions of $\mathrm{D}$ and $\mathrm{G}$ bands and $I_{\mathrm{D}} / I_{\mathrm{G}}$ intensity ratio obtained from the Raman spectra of the sample measured in three different places.

According to the data presented in table 1, D and $\mathrm{G}$ bands positions correspond to a graphitic disordered system [38] due to the bands around $1360 \mathrm{~cm}^{-1}$ and $1590 \mathrm{~cm}^{-1}$, respectively. The $I_{\mathrm{D}} / I_{\mathrm{G}}$ intensity ratio is $0.921 \pm 0.009$, slightly smaller than for carbon nanofibers produced by catalytic thermal chemical vapor deposition $(C V D)\left(I_{\mathrm{D}} / I_{\mathrm{G}}=1.35\right)$ [36]. Since $I_{\mathrm{D}} / I_{\mathrm{G}}$ ratio decreases as sample disorder decreases, then, the produced nanofibers are more ordered than the as-produced nanofibers by CVD method. According to Ren et al [39], the microstructure of carbon fibers changes along the axial direction indicating the surface heterogeneity. Moreover, the amount of amorphous carbon varied significantly in different regions. In this work, the low standard deviation shows the nanofibers are quite homogeneous, probably related to the reduced diameter of the fibers.

\section{Final conclusions}

The polyacrylonitrile mat was produced by electrospinning generating nanofiber with an average diameter of $(375 \pm 85) \mathrm{nm}$. The more appropriate processing conditions were: applied voltage of $21.8 \mathrm{kV}$, distance working of $10 \mathrm{~cm}$ and rotation of the cylinder of $24.7 \mathrm{rpm}, \mathrm{PAN} / \mathrm{DMF}$ concentration solution of $6 \% \mathrm{~m} / \mathrm{m}$ and time of material collection of 6 and $12 \mathrm{~h}$.

The thermal degradation of the PAN nanofibers obtained from electrospinning process occurred in four steps and the residual mass that remained after this degradation was 38\%, when analyzed in an inert atmosphere. 
In DSC analysis were found the glass transition temperature de values of 103 and $102{ }^{\circ} \mathrm{C}$ respectively for the PAN nanofibers obtained by electrospinning considering 6 and $12 \mathrm{~h}$.

The carbon nanofiber mat with a diameter of (186 \pm 45$) \mathrm{nm}$ was successfully obtained from the carbonization of the PAN nanofiber produced by electrospinning process. After carbonization, there occurred a reduction of $50 \%$ in the carbon nanofiber diameter in relation to the diameters of the mat before carbonization. The aspect of the mat observed was brittle and with black color, and the same presented a mass yield of $25 \%$ when compared with the no carbonized mat. The more appropriate conditions obtained in the carbonization process were: heating rate of $1{ }^{\circ} \mathrm{C} \mathrm{min}^{-1}$, starting from room temperature up to $1000^{\circ} \mathrm{C}$, remaining $1 \mathrm{~h}$ at the final temperature selected under a constant flow of nitrogen;

Raman spectroscopy analysis showed the material can be classified as disordered carbon and is quite homogeneous due to the low standard deviation for $I_{\mathrm{D}} / I_{\mathrm{G}}$ ratio which indicated the good structural quality of the carbon nanofibers.

\section{Acknowledgments}

The authors acknowledge financial support received from FAPESP, CAPES/PVNS and CNPq.

\section{ORCID iDs}

Juliana Bovi de Oliveira (iD https://orcid.org/0000-0003-2460-2930

Silvia Sizuka Oishi iil https://orcid.org/0000-0001-5540-3382

Luíza dos Santos Conejo (iD https://orcid.org/0000-0001-5533-1374

\section{References}

[1] Strelko VV, Stavitskaya S S and Gorlov Y I 2014 Proton catalysis with active carbons and partially pyrolyzed carbonaceous materials Chin. J. Catalysis 35 815-23

[2] Trung T S B et al 2015 Carbonaceous materials as catalyst supports for the enantioselective hydrogenation of (e)- $\alpha$-phenylcinnamic acid: effect of the support acidity Appl. Catalysis A 503 1-25

[3] Joshi V S et al 2010 Fabrication, characterization and electrochemical performance of single strand carbon fiber prepared by catalytic chemical vapor decomposition method Electrochim. Acta 55 2022-8

[4] Wang Q et al 2012 A review on application of carbonaceous materials and carbon matrix composites for heat exchangers and heat sinks Int. J. Refrig. 35 7-26

[5] Tsai H Y and Tseng P T 2015 Field emission characteristics of diamond nano-tip array fabricated by anodic aluminum oxide template with nano-conical holes Appl. Surf. Sci. 351 1004-10

[6] Liu C K et al 2015 Effect of carbonization temperature on properties of aligned electrospun polyacrylonitrile carbon nanofibers Mater. Des. 85 483-6

[7] ZHU X et al 2015 Application of nanomaterials in the bioanalytical detection of disease-related genes Biosens. Bioelectron. 74 113-33

[8] Wei G et al 2016 Effect of the graphitization degree for electrospun carbon nanofibers on their electrochemical activity towards $\mathrm{VO}^{2+} / \mathrm{VO}_{2}{ }^{+}$redox couple Electrochim. Acta 199 147-53

[9] Zhang X et al 2016 An electrochemical non-enzymatic immunosensor for ultrasensitive detection of microcystin-lr using carbon nanofibers as the matrix Sensors Actuators B 233 624-32

[10] Paul D R and Robeson L M 2008 Polymer nanotechnology: nanocomposites Polymer 49 33187-204

[11] Camargo P H C, Satyanarayana K G and Wypych F 2009 Nanocomposites: synthesis, structure, properties and new application opportunities Mater. Res. 12 1-39

[12] Chen C et al 2009 The influence of surface morphology and rigidity of the substrata on cell motility Mater. Lett. 63 1872-5

[13] Zare Y and Shabani I 2016 Polymer/metal nanocomposites for biomedical applications Mater. Sci. Eng. C 60 195-203

[14] Bhardwaj N and Kundu S C 2010 Electrospinning: a fascinating fiber fabrication technique Biotechnol. Adv. 28 325-47

[15] Li W 2015 Hybrid gel polymer electrolyte fabricated by electrospinning technology for polymer lithium-ion battery Eur. Polym. J. 67 $365-72$

[16] Guo Jet al 2016 Characterization and application of chondroitin sulfate/polyvinyl alcohol nanofibres prepared by electrospinning Carbohydrate Polym. $143239-45$

[17] Kim M et al 2016 Electrochemical improvement due to alignment of carbon nanofibers fabricated by electrospinning as an electrode for supercapacitor Carbon $99607-18$

[18] Low L W et al 2015 Carbonization of elaeis guineensis frond fiber: effect of heating rate and nitrogen gas flow rate for adsorbent properties enhancement J. Ind. Eng. Chem. 2837-44

[19] Guerrini L M et al 2006 Eletrofiação do poli (álcool vinílico) via solução aquosa Polímeros: Ciência e Tecnol. 16 286-93

[20] Bourourou M et al 2015 Chemically reduced electrospun polyacrilonitrile-carbon nanotube nanofibers hydrogels as electrode material for bioelectrochemical applications Carbon $87233-8$

[21] Adabi M et al 2015 Performance of electrodes synthesized with polyacrylonitrile-based carbon nanofibers for application in electrochemical sensors and biosensors Mater. Sci. Eng. C 48 673-8

[22] Brquim 2010 http://brquim.com.br/fispq/10547.pdf(Accessed: 07 August 2016)

[23] Wu G P et al 2009 Comparative investigation on the thermal degradation and stabilization of carbon fiber precursors Polym. Bull. 62 $667-78$

[24] Ribeiro R F 2010 Caracterização de fibras e filmes de poliacrilonitrila extrudada Program of Pos-Graduation in Aeronautical and Mechanical Engineering in area of Physics and Chemistry of Aerospace MaterialsSão José dos Campos 
[25] Xue T J, Mckinney M A and Wilkie C A 1997 The thermal degradation of polyacrylonitrile Polym. Degrad. Stab. 58 193-202

[26] Peeples L H et al 1990 Carbon fibers: formation, structure and properties Carbon 28707

[27] Brito C A R Jr et al 2011 Estudo termogravimétrico da poliacrilonitrila com o plastificante glicerol In Annals of the 11th Brazilian Congress of Polymers (Campos do Jordão)

[28] Gazard M 1986 Handbook of Conducting Polymers. v.1 (New York: Marcel Dekker Inc.)

[29] Santos V M 2009 Estudo dos filmes de poliacrilonitrila modificados pela adição de clorofilas, citocromo C, Fe (II) E Fe (III) Dissertation -Program of Pos-Graduation in Chemistry Universidade Federal do Espírito Santo. Vitória

[30] Brandrup J, Immergut E H and Grulke E A 2003 Polymer Handbook vol 2 4th edn (New York: Wiley-Interscience)

[31] Shin H K et al 2014 Preparation and characterization of polyacrylonitrile-based carbon fibers produced by electron beam irradiation pretreatment J. Ind. Eng Chem. 203789-92

[32] Rezende M C, Costa M L and Botelho E C 2011 Compósitos Estruturais: Tecnologia e Prática (São Paulo: Artliber) pp 34-7

[33] Lobo A O et al 2005 Caracterização de materiais carbonosos por espectroscopia raman Rev. Bras. Aplicações Vácuo 24 98-103

[34] Jauris I et al 2011 Produção de nanotubos de carbono via técnica de deposição química de vapor Disc. Scientia. Série: Ciências Naturaise Tecnológicas, S. Maria. 12 125-37 https://www.periodicos.unifra.br/index.php/disciplinarumNT/article/view/1285/1217

[35] Oishi S S 2013 Produção e Caracterização de Carbono Vítreo Monolítico a Partir das Resinas Poliarilacetileno e Furfurílica ThesisProgram of Pos-Graduation in Mechanical Engineering in area of Materials Universidade Estadual Paulista, Faculdade de Engenharia de Guaratinguetá. Guaratinguetá

[36] Ramos A, Cameán I and García A B 2013 Graphitization thermal treatment of carbon nanofibers Carbon 59 2-32

[37] Baldan M R et al 2007 Raman validity for crystallite size La determination on reticulated vitreous carbon with different graphitization index Appl. Surf. Sci. 254 600-3

[38] Takai Ket al 2003 Structure and electronic properties of a nongraphitic disordered carbon system and its heat-treatment effects Phys. Rev. B 67 1-11

[39] Ren G Z et al 2015 Microstructural heterogeneity on the cylindrical surface of carbon fibers analyzed by Raman spectroscopy Xinxing Tan Cailiao/New Carbon Mater. 30 476-80 